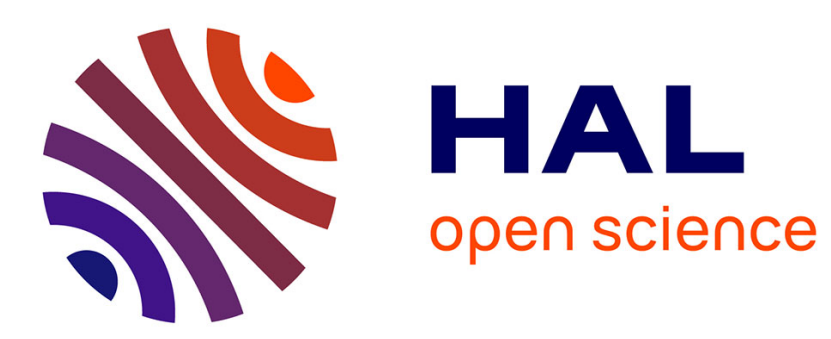

\title{
On the glass transition temperature Tg against molar volume Vm plotting in arsenoselenide glasses
}

M. Shpotyuk, J. Szlęzak, Y. Shpotyuk, C. Boussard-Plédel, B. Bureau, V. Balitska, V. Boyko, O. Shpotyuk

\section{- To cite this version:}

M. Shpotyuk, J. Szlęzak, Y. Shpotyuk, C. Boussard-Plédel, B. Bureau, et al.. On the glass transition temperature $\mathrm{Tg}$ against molar volume Vm plotting in arsenoselenide glasses. Journal of NonCrystalline Solids, 2020, 528, pp.119758. 10.1016/j.jnoncrysol.2019.119758 hal-02443576

\author{
HAL Id: hal-02443576 \\ https://hal.science/hal-02443576
}

Submitted on 13 Feb 2020

HAL is a multi-disciplinary open access archive for the deposit and dissemination of scientific research documents, whether they are published or not. The documents may come from teaching and research institutions in France or abroad, or from public or private research centers.
L'archive ouverte pluridisciplinaire HAL, est destinée au dépôt et à la diffusion de documents scientifiques de niveau recherche, publiés ou non, émanant des établissements d'enseignement et de recherche français ou étrangers, des laboratoires publics ou privés. 


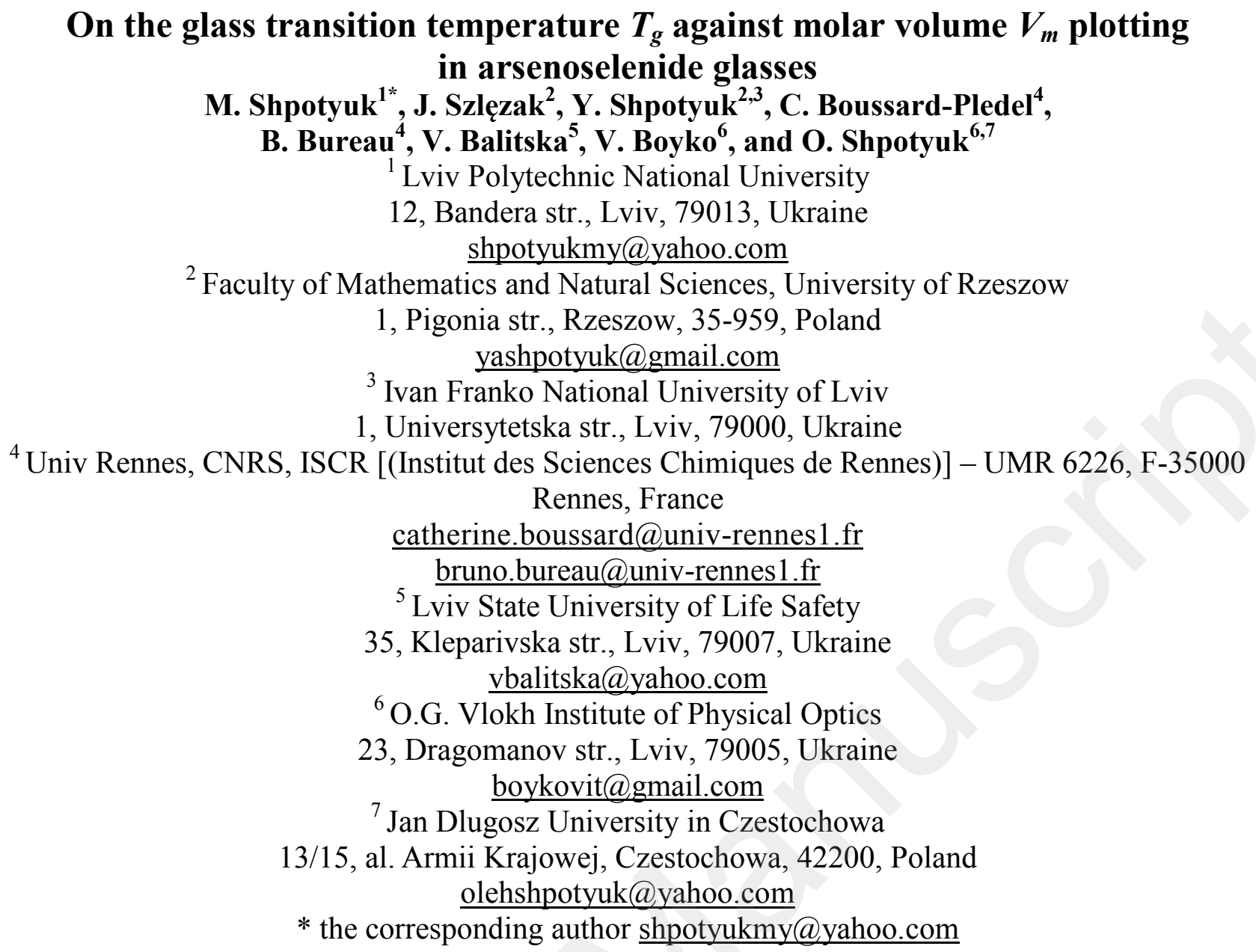

\begin{abstract}
Dependence of glass transition temperature $T_{g}(\mathrm{~K})$ on overall mean bonding energy $E(\mathrm{~kJ} / \mathrm{mol})$ in arsenoselenide glass reexamined under per-atom calculations is shown to obey linearized master equation $T_{g} \cong 418 \cdot(E-1.13)$. Compositional variations in $T_{g}$ against molar volume $V_{m}$ are plotted for g-As ${ }_{x} \mathrm{Se}_{100-x}$ taken within $(0 \leq x \leq 65)$ domain assuming preferential cohesive Van der Waals (VDW) bonding between network-constituting entities. The $T_{g}$ values are found to vary as inverse- $\alpha$-th power of $V_{m}$, attaining distinct values for different networks, in part, 0D-molecular $(\alpha=6 / 3=2)$, 1Dchained ( $\alpha=5 / 3), 2 \mathrm{D}$-layered $(\alpha=4 / 3)$, and 3D-spatial $(\alpha=3 / 3=1)$. These variations originated from macroscopic geometry of VDW interaction are linearized in $\log$-log presentation for networks dominated with chain-like 1 D-entities $(0 \leq x<\sim 8)$ and cross-linked 3D-entities $(\sim 8<x<30-33)$, while demonstrate non-linear behavior for cross-linked 3D- and layered 2D-entities $(30-33<x<40)$, and

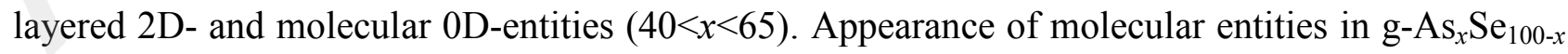
$(40<x<65)$ results in self-terminated loop in $\log$-log plotting of $T_{g}\left(1 / V_{m}\right)$ dependence.
\end{abstract}

Keywords: chalcogenide glass; arsenoselenides; glass transition temperature; molar volume; glassforming network; Van der Waals interaction 


\section{Introduction}

The glass transition phenomenaon defined merely by characteristic temperature where supercooled liquid is frozen in a solid state (known as glass transition temperature $T_{g}$ [1-3]) represents fundamental property of vitreous substances such as chalcogenide glasses (ChG), which play a crucial role in many fields of their applications stretching from phase-change phenomena to multi-cyclic exploitation of externally-induced functionality [4,5]. That is why compositional variations in the $T_{g}$ values [7-13], and their interrelation with other materials-specific parameters, which are known to be strongly dependent on cohesive forces and rigidity of covalent-type networks $[10,14,15]$, have attracted a widespread attention within a glass-science community.

In general, the glass transition temperature $T_{g}$ serves as indicative of onset in cooperative rearrangement of some structural entities composing glassy network built of atoms, molecules, clusters, segmental chains, layers, etc., where viscosity $\eta$ overcomes the critical barrier approaching $\eta_{c} \cong 10^{13}$ Poise $[1,8]$. In the Tichy's interpretation [10], to reach the higher mobility of network constituents in $\mathrm{ChG}$, one should supply two energetic contributions, these being firstly to disturb glassy matrix creating such mobile entities, and then to reorient them for moving in a space. The former is evidently relevant to strength of primary covalent bonding, that is number and type of network-composing covalent bonds in $\mathrm{ChG}[7,8]$. At a global scale of compositional variation, the $T_{g}$ changes are defined by superposition of these stronger covalent bonds with weaker secondary bonds, mainly of intermolecular or Van der Waals (VDW) type, governing cooperative rearrangement in glass-forming region $[7,8]$.

This approach allows prediction of compositional $T_{g}$ variations in $\mathrm{ChG}$ in terms of cohesive VDW bonding energy for principal atomic units forming movable segmental entities in their structure. Thus, assuming the Arrhenius relation for viscosity with an effective activation energy of atomic segmental motion of polymer chains or slipping movements of distorted layers $\left(E=E_{0} \cdot n^{\mathrm{Z}-1}\right)$ defined as cooperative rearrangement of structural units including $n \cong 5$ atoms $\left(E_{0} \cong 0.15 \mathrm{eV}\right), \mathrm{K}$. Tanaka [8] derived simple relationship between $T_{g}$ values and average coordination numbers per atom $Z$ for $\mathrm{ChG}$ and molecular materials with hydrogen bonding in the range of $1 \leq Z \leq 2.7$ : 


$$
\ln \left(T_{g}\right)=1.6 \cdot Z+2.3
$$

The above eq. (1) describes compositionally driven $T_{g}$ variations in covalent glassy networks possessing zero- (0D), one- (1D) and two-dimensional (2D) glass-forming structural elements. When strength of VDW bonding approaches dissociation energy of primary network-constituting covalent bonds, as it was expected for A-rich over-stoichiometric ChG of $\mathrm{A}_{x} \mathrm{~B}_{100-x}$ systems (where $\mathrm{A}$ $=\mathrm{As}, \mathrm{Ge} ; \mathrm{B}=\mathrm{S}, \mathrm{Se}$ ), the $T_{g}$ values are supposed [8] to be nearly constant due to competitive contribution from weaker homonuclear A-A bonds fractured under glass transition. But this feature is not supported by $T_{g}(Z)$ dependences for g-As-S [4], g-As-Se [4,16-18], g-Ge-S [4,19], and g-GeSe $[4,16,20]$, which demonstrate rather decreasing tendency for over-stoichiometric compositions (after reaching more or less pronounced $T_{g}$ maximum at the stoichiometry point) than compositionally-invariant trend.

Within other approach [13], the VDW interactions are considered as completely responsible for cooperative rearrangement of some atomic units at the glass transition, so that changes in $T_{g}$ values arise from variations in preferential type of these interactions between structural entities composing glass-forming network, which can be defined by molar volume $V_{m}$. Thus, the $T_{g}$ values were found to vary with glass composition as the inverse- $\alpha$-th power of molar volume $V_{m}$ :

$$
T_{g} \sim\left(1 / V_{m}\right)^{\alpha}
$$

where power index $\alpha=6 / 3=2$ stands for $0 \mathrm{D}$-dimensional networks characterized by interaction between point-like entities (such as sulphur rings $\mathrm{S}_{8}$ ), $\alpha=5 / 3 \approx 1.67$ is character for preferential 1Ddimensional networks dominated by interaction between chalcogen chains, $\alpha=4 / 3 \approx 1.33$ corresponds to $2 \mathrm{D}$-dimensional networks built of atomic sheets, and $\alpha=3 / 3=1$ is ascribed to $3 \mathrm{D}$-dimensional networks, where VDW interactions are ascribed to more extended multi-atomic formations. With respect to the structure of over-stoichiometric arsenic sulphides/selenides [4], the latter can be imagined as cage-like molecular clusters and their network derivatives. But this suggestion was not clarified in [13] because of limitation to only under-stoichiometric glasses of As-S system $(Z<2.40)$. 
This study is aimed to recognize compositional $T_{g}$ variations in ChG of canonical $g-\mathrm{As}_{x} \mathrm{Se}_{100-x}$ system possessing pronounced glass-forming ability in a wide range of compositions ranging from pure g-Se $(Z=2.00)$ to highly As-enriched $g-\mathrm{As}_{65} \mathrm{Se}_{35}(Z=2.65)$.

\section{Experimental}

The arsenoselenide $g-\mathrm{As}_{x} \mathrm{Se}_{100-x}$ glassy alloys $(x=0,2,4,5,6,8,10,12.5,15,17.5,20,22.5,25$, $27.5,29,33,35,37,40,45,50,55,60,65)$ were prepared by conventional melt-quenching from high-purity elemental precursors (As and Se of $5 \mathrm{~N}$ purity) stored under Ar atmosphere. The sealed ampoules were placed into a rocking furnace, heated up to $650{ }^{\circ} \mathrm{C}$ in $6 \mathrm{~h}$ and homogenized at this temperature for $10 \mathrm{~h}$. Then, ampoules were placed vertically (no rocking), cooled down to $500{ }^{\circ} \mathrm{C}$ and quenched into a water. All samples were annealed just after quenching at $\left(\mathrm{T}_{\mathrm{g}}-15\right){ }^{\circ} \mathrm{C}$ for $1 \mathrm{~h}$. More details on synthesis procedure can be found elsewhere [21,22].

The synthesized specimens annealed below glass transition temperature $T_{g}$ were amorphous, as it follows from their powder X-ray diffraction patterns showing only diffuse "amorphous" halos, character conch-like fracture of fresh-ingot cut sections and far IR transparency. Macroscopic densities $\rho\left( \pm 0.005 \mathrm{~g} \cdot \mathrm{cm}^{-3}\right)$ determined at room temperature by Archimedes displacement in ethanol using Mettler Toledo balances, and mid-onset glass transition temperatures $T_{g}\left( \pm 3{ }^{\circ} \mathrm{C}\right)$ determined from DSC scanning under $10 \mathrm{~K} / \mathrm{min}$ heating rate using TA Instrument Q20 calorimeter, testify in a favor of complete adequacy of the prepared alloys with known counterparts from this binary system $[4,16]$. The values of molar volume $V_{m}$ and mean inter-atomic spacing $d_{s}{ }^{m}$ of these glasses derived from their atomic densities $\rho$ are reproduced in Fig. 1. They show an obvious global minimum-type tendency near stoichiometry $Z=2.40(x=40)$ superimposed on more stretched local maximum positioned at $Z \cong 2.55(x \cong 55)$.

\section{Results and discussion}

In the realistic glass-forming structures, the glass transition phenomena are defined by averaged contribution of strong interatomic covalent bonding superimposed by weaker VDW interaction of 
super-structural units forming a glassy network $[8,10,11,13,15]$. Within compositional $T_{g}$ against $V_{m}$ variation, the input of stronger covalent bonding can be assumed as giving continuous power-type dependence with nearly constant power index defined by overall mean bonding energy $E$ dependent on a glass composition. Thus, the dominated variations in $T_{g}$ against $V_{m}$ plotting can be ascribed to changes in the preferential VDW interaction for principal network-forming structures, which can be accepted as prototypes of some macroscopic geometrical configurations analyzed, e.g., in [23].

\subsection{Compositional variations in g-As-Se defined by overall mean bonding energy.}

Despite illusory simplicity, reliable correlation between glass transition temperature $T_{g}$ and overall mean bonding energy per atom $E$ in ChG like g-As-Se seems not adequately understandable.

Nearly a quarter century ago, Tichý and Tichá [10] suggested the simple master equation for $T_{g}$ dependence on averaged bonding strength $E$ in covalent networks derived for 186 representative ChG:

$$
T_{g} \cong 311 \cdot(E-0.9) \text {. }
$$

However, this equation cannot be accepted as describing realistic $T_{g}$ against $E$ correlations in ChG because of incorrect determination of overall mean bonding energy per atom $E$. Indeed, the authors [10] defined this energy through two contributions, these being (i) mean energy of average cross-linking originated merely from heteronuclear covalent bonding and (ii) average energy of the 'remaining matrix' originated from homonuclear covalent bonding. To be validated for ChG, both components should be defined per atom of a glassy network (i.e. in respect to atomic fraction of glass ingredients), while the latter (the 'remaining matrix' energy) is introduced in [10] as product of dividing on a half of coordination number $Z / 2$, i.e. respectively to the number of chemical bonds. As a result, the overall mean bonding energies per atom $E$ for $\mathrm{g}-\mathrm{As}_{x} \mathrm{Se}_{100-x}$ determined following the procedure described in [10] are systematically under-estimated, i.e. the calculated $E$ values occur to be less than realistic mean bonding energies for glasses in this system.

In application to g-As-Se, this discrepancy is clearly evident with simple structural-statistical assumptions for stoichiometry in this system obeying ideal continuous reticulation model 
(alternatively known as $\mathrm{CO} \mathrm{CBN}$, i.e. chemically-ordered covalent bond network model $[4,5]$ ) derived by Yang et al. [18]. These authors [18] calculated overall mean bonding energies per atom $E$ for these glasses taking into account different types of nearest-neighbor environments possible around Se and As atoms, and using known energies for separate covalent bonds reported by Pauling [24]. Under such approach, these energies should principally coincide with those calculated as suggested in [10], showing close similarity to linear dependence derived from experimental elastic moduli and density measurements for $\mathrm{g}-\mathrm{As}_{x} \mathrm{Se}_{100-x}$ with distinct maximum at the stoichiometry point $(x=40)$. Linear compositional dependence of $E$ albeit with less pronounced maximum at $x=40$ is indeed observed [18], but it differs essentially from that non-linear one calculated in respect to [10] due to systematically under-estimated mean bonding energies $E$ for non-stoichiometric glasses (see Fig. 2). Of course, for stoichiometric $\mathrm{g}-\mathrm{As}_{2} \mathrm{Se}_{3}$ having no homonuclear bonds in respect to $\mathrm{CO} \mathrm{CBN}$ model, and g-Se possessing $Z=2$ with only homonuclear Se-Se bonds, the calculated energies coincide. For convenience reason, we also reproduce data on the overall mean bonding energies $E$ calculated per one bond in $\mathrm{g}-\mathrm{As}_{x} \mathrm{Se}_{100-x}$ (depicted by black solid line on Fig. 2) known as cohesive energies $(C E)$.

It worth mentioning the sharper linear decrease in the experimental $E$ values obtained from elastic moduli measurements for $\mathrm{g}-\mathrm{As}_{x} \mathrm{Se}_{100-x}$ at $x>40$ was reasonably explained in [18] as resulting from formation of molecular-like structural fragments in over-stoichiometric glasses of this system.

In general, the overall mean bonding energy per atom $E$ for $\mathrm{ChG}$ is simply defined as the weighted total energy of bonds per atom (divided by the total number of bonds) obeying chosen statistics in a glass-forming network [7]. Thus, the $E$ values for $\mathrm{g}-\mathrm{As}_{x} \mathrm{Se}_{100-x}$ can be found accepting bond-dissociation energies (in part, $E_{\mathrm{As}-\mathrm{Se}}=174 \mathrm{~kJ} / \mathrm{mol}, E_{\mathrm{As}-\mathrm{As}}=134 \mathrm{~kJ} / \mathrm{mol}$, and $E_{\mathrm{Se}-\mathrm{Se}}=184 \mathrm{~kJ} / \mathrm{mol}$ [24]) and preferential type of CBN giving relative concentration of these bonds in a.u. $\left(n_{\mathrm{As}-\mathrm{Se}}, n_{\mathrm{As}-\mathrm{As}}\right.$ and $\left.n_{\mathrm{Se}-\mathrm{Se}}\right)$ :

$$
E=Z / 2 \cdot\left(n_{\mathrm{As}-\mathrm{Se}} \cdot E_{\mathrm{As}-\mathrm{Se}}+n_{\mathrm{As}-\mathrm{As}} \cdot E_{\mathrm{As}-\mathrm{As}}+n_{\mathrm{Se}-\mathrm{Se}} \cdot E_{\mathrm{Se}-\mathrm{Se}}\right) .
$$

For $g-\mathrm{As}_{x} \mathrm{Se}_{100-x}$ obeying CO CBN model, these concentrations can be respectively determined for under-stoichiometric ( $x \leq 40, \mathrm{Z} \leq 2.4)$ and over-stoichiometric $(x \geq 40, \mathrm{Z} \geq 2.4)$ domains [25,26]: 


$$
\begin{aligned}
& n_{\mathrm{As}-\mathrm{Se}}=0.06 \cdot x / Z, n_{\mathrm{As}-\mathrm{As}}=0, n_{\mathrm{Se}-\mathrm{Se}}=(2-0.05 \cdot x) / Z ; \\
& n_{\mathrm{As}-\mathrm{Se}}=0.04 \cdot x / Z, n_{\mathrm{As}-\mathrm{As}}=(3-0.05 \cdot x) / Z ; n_{\mathrm{Se}-\mathrm{Se}}=0 .
\end{aligned}
$$

As it was expected, the overall mean bonding energies $E$ for $g-\mathrm{As}_{x} \mathrm{Se}_{100-x}$ calculated in respect to the above algorithm (see Fig. 2) occurred to be completely the same as calculated by Yang et al. [18]. This result can be also achieved in original Tichý and Tichá approach [10] recalculating the average energy of the 'remaining matrix' originated from homonuclear bonding per one atom of a glass (dividing on overall atomic fraction of glass components instead of half of coordination number $Z / 2)$.

Now, we can respectively reproduce the $\log$ - $\log$ plotting of the overall mean bonding energy per atom $E$ against inverse molar volume $V_{m}$ in the $g-\mathrm{As}_{x} \mathrm{Se}_{100-x}$ (Fig. 3). The $\ln E$ against $\ln \left(1 / V_{m}\right)$ curve can be linearized for under-stoichiometric arsenoselenide glasses $(x \leq 40, Z \leq 2.4)$ with the adjusted coefficient of determination $R_{a d j}^{2}=0.996$ :

$$
\ln E=1.26 \cdot \ln \left(1 / V_{m}\right)+8.89
$$

Thus, the linear $\ln E$ against $\ln \left(1 / V_{m}\right)$ plotting is expected with compositional variations in $g$ $\mathrm{As}_{x} \mathrm{Se}_{100-x}$, provided the glass transition temperature $T_{g}$ is defined by the overall mean bonding energy per atom $E$ (which also determines the averaged bond strength in a glassy matrix).

Other remarkable feature in compositionally-variable $\mathrm{g}-\mathrm{As}_{x} \mathrm{Se}_{100-x}$ emerged from preferential intra-atomic covalent bonding is distinct loop formed in a growing coordination number $Z$ sequence (with increased As content) by over-stoichiometric glasses with $x>40$. The down-going part of this loop is formed by glasses with increasing molar volumes $V_{m}$ on Fig. $1(x=40,45,50,55)$, while those with decreasing $V_{m}(x=60,65)$ terminate this dependence in the loop as shown in Fig. 3.

With corrected overall mean bonding energies per atom $E$ for $\mathrm{g}-\mathrm{As}_{x} \mathrm{Se}_{100-x}$ as justified above, it seems interesting to compare realistic $T_{g}$ against $E$ dependence with that predicted by Tichý and Tichá [10] via eq. (3), the linearized plotting of such correction being depicted on Fig. 4. Our data for these glasses can be satisfactorily least-square adjusted to the straight line red-coloured on Fig. 4 with more than $30 \%$ higher slope $\left(R_{a d j}{ }^{2}=0.907\right)$ :

$$
T_{g} \cong 418 \cdot(E-1.13) \text {. }
$$


Thereby, the linearized $T_{g}$ against $E$ dependence for $g-\mathrm{As}_{x} \mathrm{Se}_{100-x}$ occurs indeed to be systematically up-shifted along $T_{g}$ scale (approximately on $\sim 3 \%$ for $\mathrm{g}$-Se and $\sim 10 \%$ for stoichiometric $\mathrm{g}-\mathrm{As}_{2} \mathrm{Se}_{3}$ ) in respect to the approximation given by Tichý and Tichá via eq. (3).

\subsection{Glass transition temperature $T_{g}$ against molar volume $V_{m}$ plotting in g-As-Se.}

Thereby, covalent interactions alone are failure to predict realistic $T_{g}$ vs. $V_{m}$ plotting in ChG like g- $\mathrm{As}_{x} \mathrm{Se}_{100-x}$, testifying in a favour of $T_{g}$ variations essentially governed by VDW interactions.

For 0D-networks built of randomly-packed hard spheres (atoms), simple interatomic interactions obviously prefer, thus giving thermal energy at glass transition $k \cdot T_{g}$ proportional to the energy of VDW cohesive interaction between permanent or transient dipoles varying as the inversesixth power of inter-dipole distance $1 / d^{6}$ [23]. Since simple cubic dependence on $d$ is expected for molar volume $V_{m}$, this case results in inverse-second power of molar volume $V_{m}$ plotting (2).

If inter-chain interactions define glass structure (1D-networks), this $T_{g}\left(1 / V_{m}\right)$ plot (2) attains somewhat reduced power index $\alpha=5 / 3$, as was shown in [13]. In fact, this is the case of VDW interaction between infinitely long thin cylinders in a parallel configuration far apart $d$ distance with free energy proportional to $1 / d^{5}[23]$.

If 2D-entities like atomic quasi-layers define glass structure, the power index $\alpha$ in plot (2) continues further dropping to $4 / 3$. This case can be simulated as preferential VDW interaction geometry involving infinitely long cylinders in perpendicular configuration far apart $d$ distance with free energy proportional to $1 / d^{4}[23]$.

Finally, for most spatially extended 3D-structures, this plot (2) obeys $\alpha$ index tending towards 1. This case represents geometry of VDW interaction between small spheres of defined radius far from other sphere of radius much greater than distance $d$ between them, which results finally in free energy of VDW interaction proportional to $1 / d^{3}[23]$.

Therefore, the above deviations in the preferential geometry of VDW interaction varying $T_{g}$ against $\left(1 / V_{m}\right)$ plot $(2)$ can be linearized in log-log presentation:

$$
\ln \left(T_{g}\right)=a+b \cdot \ln \left(1 / V_{m}\right)=a-b \cdot \ln \left(V_{m}\right),
$$


where $a$ is the materials-related constant, and slope of this linearized dependence $b$ represents some value directly related to $\alpha$ index in the inverse- $\alpha$-th power plot (2).

The $\ln T_{g}$ against $\ln \left(1 / V_{m}\right)$ plotting reconstructed from experimentally measured glass transition temperatures $T_{g}$ and atomic densities $\rho$ for $\mathrm{g}-\mathrm{As}_{x} \mathrm{Se}_{100-x}$ is depicted in Fig. 5. A few characteristic regions can be distinguished on this graph with increase in the average coordination number $Z$ from

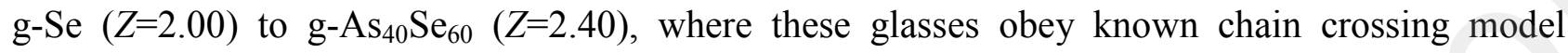
$[5,18,27-33]$, these being as follows $0 \leq Z<\sim 2.08 ; \sim 2.08<Z<\sim(2.29-2.33)$ and $\sim(2.29-2.33)<Z<2.40$.

Firstly, within $2.0 \leq Z<\sim 2.08$ range $(0 \leq x<\sim 8)$, the linearized log-log plotting (2) demonstrates steep dependence with slope $b$ approaching 4.5 (linearization with adjusted coefficient of determination $\left.R_{a d j}{ }^{2}=0.998\right)$. In respect to Raman scattering [18] and XPS [29,31] studies, the As-Se glasses in this compositional range possess 1D-structures built of Se chains stretching between some branchy points formed by trigonal $\mathrm{AsSe}_{3 / 2}$ pyramids (thus forming network of $\mathrm{AsSe}_{3 / 2^{-}}$ branched Se-chains in preferential parallel configuration).

At further increase in As content in $\mathrm{g}^{-\mathrm{As}_{x}} \mathrm{Se}_{100-x}$ within $\sim 2.08<Z<\sim(2.30-2.33)$ domain $(\sim 8<x<\sim 29-33)$, chain-like entities occur in orthogonal configuration due to frequent cross-linking. The studied glasses became, in fact, 3D-structured $[18,30]$. The slope $b$ of the linearized $\log$ - $\log$ plot (3) drops to 2.5 (linearization with $R_{a d j}{ }^{2}=0.982$ ), which is in good respect with expected $\sim 70 \%$ dropping in the power index $\alpha$ when going from 1D-structures $(\alpha=5 / 3)$ to 3D-ones $(\alpha=1)$.

Within $\sim(2.29-2.33)<Z<2.40$ domain (corresponding to $\sim 29-33<x<40$ ), the log-log plot (2) losses its linearity tending to ever steeper dependence (the slope $b$ estimated for glasses with $x=40$ and $x=37$ reaches 11.3 , Fig. 5). In respect to characterization due to Raman scattering [18] and XPS studies [30,31], this region in g-As-Se is distinguished by transition to layer-type 2D-entities, which dominate in stoichiometric $\mathrm{g}-\mathrm{As}_{2} \mathrm{Se}_{3}$, i.e. non-linearity in this compositional domain results from superposition of cross-linked 3D- and layered 2D-structures in g-As $\mathrm{Se}_{100-x}$ with $\sim 30-33<x<40$.

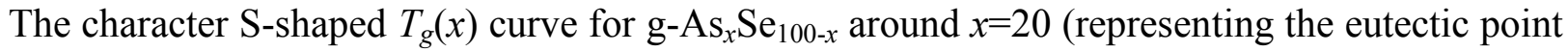
on the phase diagram of As-Se system [32]) was pointed out by Phillips in his famous paper [35]. Contrary to g-As-S, where phase separation is merely dominated in a whole chalcogen-rich region, 
such behavior was accepted as an evidence of incipient immiscibility in this glass-forming system. After Feltz's et al. opinion [16], the composition of $\mathrm{AsSe}_{3}$ (viz. g- $\mathrm{As}_{25} \mathrm{Se}_{75}$ ) in this system, where $\mathrm{AsSe}_{3 / 2}$ pyramids are interconnected by $-\mathrm{Se}-\mathrm{Se}$ - bridging dimers (forming $-\mathrm{Se}_{2}=\mathrm{As}-\mathrm{Se}-\mathrm{Se}-\mathrm{As}=\mathrm{Se}_{2}{ }^{-}$ network) can be accepted as chemically ordered glass-forming compound in non-crystalline state. Changes in the slope of dielectric constant curve at this composition also suggest that $=$ As-Se-As= bridges character for stoichiometric $\mathrm{g}-\mathrm{As}_{40} \mathrm{Se}_{60}$ are absent or exists only in negligible concentration in $\mathrm{g}-\mathrm{As}_{x} \mathrm{Se}_{100-x}$ at $x<25$.

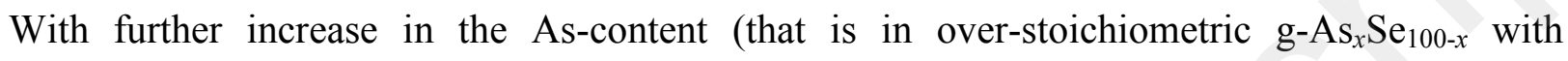
$40<x<65$ ), the glass transition temperature $T_{g}$ decreases in unison with decrease in atomic density $\rho$ (Table 1). The recalculated values of molar volume $V_{m}$ for these glasses demonstrate slight stretched maximum near $x \cong 55$ (see Fig. 1). Such changes result in a reverse trend in $\log$-log plot (2) with evidently increasing tendency in the slope $b$ with ever growing $x$ parameter. As a result, the $T_{g}$ values are completely renewed in over-stoichiometric $\mathrm{g}-\mathrm{As}_{x} \mathrm{Se}_{100-x}$ samples at the end of this region $(x=60,65)$, creating in such a way the self-closed $T_{g}\left(1 / V_{m}\right)$ loop as it clearly demonstrated in Fig. 5.

These changes find reasonable explanation within known models on structural evolution in Asrich $\mathrm{g}_{-} \mathrm{As}_{x} \mathrm{Se}_{100-x}$ composed of molecular-type entities [18,30,33,36]. With first As additions to g$\mathrm{As}_{2} \mathrm{Se}_{3}$, the layered 2D-network is essentially destroyed, giving rise to mixed structures built of 0Dentities (partially and/or completely-polymerized realgar-type $\mathrm{As}_{4} \mathrm{Se}_{4}$, dimorphite-type $\mathrm{As}_{4} \mathrm{Se}_{3}$ or $\mathrm{As}_{4}$ cage-like molecules and their network derivatives), accommodated in a preferential 3D-network of As-Se remainder $[18,36]$. Thus, from a viewpoint of VDW interactions, the governing role in such glasses belongs to admixture of destroyed 2D-structural entities possessing power index $\alpha$ in eq. (2) approaching 4/3 and 3D-entities having $\alpha$ close to 1 with $0 \mathrm{D}$-structures of molecular-type $\mathrm{As}_{4} \mathrm{Se}_{n}$ clusters giving steeper slope $(\alpha=2)$, the latter being evidently dominated with As content.

Noteworthy, the dimorphite-type $\mathrm{As}_{4} \mathrm{Se}_{3}$ ring-like molecular cages (and their network derivatives) possessing close-to-spherical symmetry [37,38] evidently dominate in $\mathrm{g}-\mathrm{As}_{x} \mathrm{Se}_{100-x}$ at higher As content $(x>55)$ [18,36], thus ensuring extra-rapid dropping in the glass transition temperature $T_{g}$ owing to rotational diffusion appropriate to extremely low network connectivity 
(enhanced plasticity of glass-forming network) [37]. In fact, these structural species ensure terminated loop-forming trend in a log-log plotting (2) as shown in Fig. 5 for last three compositions in this row $(x=55,60,65)$. Therefore, it should be emphasized that loop-forming trend in $T_{g}\left(1 / V_{m}\right)$ dependence is produced in $g-\mathrm{As}_{x} \mathrm{Se}_{100-x}$ by domination of molecular 0D-structural entities (such as dimorphite-type $\mathrm{As}_{4} \mathrm{Se}_{3}$ ring-like cages) over layered 2D- and spatially cross-linked 3D-structures of As-Se remainder.

By finalizing, the above consideration discloses speculative character of some attempts to ascribe local maximum in the observed compositional $T_{g}(x)$ dependence near mean coordination number $Z$ approaching 2.06-2.08 in physically-aged $g-\mathrm{As}_{x} \mathrm{Se}_{100-x}$ [17] and $\mathrm{g}-\mathrm{Ge}_{x} \mathrm{Se} \mathrm{e}_{100-x}$ [39] to topological threshold into super-flexible state. Realistically, in this domain, structure of $g-\mathrm{As}_{x} \mathrm{Se}_{100-x}$ changes from 1D-chain network with only some branchy points to spatially-extended cross-linked 3D-network, the respective $T_{g}\left(1 / V_{m}\right)$ dependences being depicted on Fig. 5 by straight lines with slopes $b$ approaching 4.5 and 2.5, respectively. Under physical ageing at ambient temperature $T_{a}$, both lines are up-shifted due to increased $T_{g}$. However, in ChG with compositions closer to pure Se, this effect is merely suppressed due to short distance from $T_{g}$. Thus, the resulting changes produce local maximum in $\Delta T_{g}$ for $g-\mathrm{As}_{x} \mathrm{Se}_{100-x}$ near $x \cong 8$, as it is clearly evidenced from Fig. 5.

\section{Conclusions}

It is shown that dependence of glass transition temperature $T_{g}(\mathrm{~K})$ on overall mean covalent bonding energy $E(\mathrm{~kJ} / \mathrm{mol})$ for $\mathrm{g}-\mathrm{As}_{x} \mathrm{Se}_{100-x}$ critically examined under energy calculations performed per one atom of a glass network obeys the linearized master equation defined as $T_{g} \cong 418 \cdot(E-1.13)$. Compositional variations in $T_{g}$ against molar volume $V_{m}$ are plotted for $\mathrm{g}-\mathrm{As}_{x} \mathrm{Se}_{100-x}$ taken from whole glass-forming region $(0 \leq x \leq 65)$ assuming preferential cohesive Van der Waals (VDW) bonding between network-constituting entities. The $T_{g}$ values are found to vary as the inverse- $\alpha$-th power of molar volume $V_{m}$ in arsenoselenide glasses, attaining several distinct values for different networks, in part, 0D-molecular $(\alpha=6 / 3=2)$, 1D-chained $(\alpha=5 / 3)$, 2D-layered $(\alpha=4 / 3)$, 3D-spatial $(\alpha=3 / 3=1)$. These variations originated from preferential geometry of VDW interaction between 
network-constituting elements are linearized in log-log presentation for specific network-forming domains, composed of chain-like 1D-entities $0 \leq x<\sim 8)$ and cross-linked 3D-entities $(\sim 8<x<30-33)$, while they demonstrate complicated non-linear behavior for networks composed of mixed crosslinked 3D- and layered 2D-entities (30-33<x<40), as well as layered 2D- and molecular 0D-entities $(40<x<65)$. Appearance of partially and/or completely-polymerized $\mathrm{As}_{4} \mathrm{Se}_{4}, \mathrm{As}_{4} \mathrm{Se}_{3}$ and $\mathrm{As}_{4}$ molecular-type entities in over-stoichiometric g-As $\mathrm{Se}_{100-x}(40<x<65)$ results in terminated loopforming trend in log-log plotting of $T_{g}\left(1 / V_{m}\right)$ dependence.

\section{Acknowledgement}

The paper is a part of research done within the projects No 0119U100357 and 0117U007189 funded by Ministry of Education and Science of Ukraine. This research is supported by POLONIUM common action program (2018-2019) in respect to bilateral Agreement on scientifictechnical cooperation between Polish and French governments.

\section{References}

1. Angell C.A., Ngai K.L., McKenna G.B., McMillan P.F., Martin S.W. Relaxation in glassforming liquids and amorphous solids. - J. Appl. Phys. 88 (2000) 3113-3157.

2. Cangialosi D. Dynamics and thermodynamics of polymer glasses. - J. Phys.: Condens. Matter. 26 (2014) 153101-1-153101-19.

3. Zanotto E.D., Mauro J.C. The glassy state of matter: Its definition and ultimate fate. - J. NonCryst. Solids 471 (2017) 490-495.

4. Feltz A. Amorphous Inorganic Materials and Glasses. - VCH Publ., Inc., Weinheim-New YorkBasel-Cambridge-Tokyo, 1993. 446 pp.

5. Tanaka K., Shimakawa K. Amorphous Chalcogenide Semiconductors and Related Materials. New York-Dordrecht-Heidelberg-London: Springer. 2011. 242 pp.

6. Van Uitert L.G. Relations between melting point, glass transition temperature, and thermal expansion for inorganic crystals and glasses. - J. Appl. Phys. 50 (1979) 8052-8061. 
7. Rao K.J., Mohan R. Glass transition in As-Se glasses. - J. Phys. Chem. 84 (1980) 1917-1919.

8. Tanaka K. Glass transition of covalent glasses. - Solid State Commun. 54 (1985) 867-869.

9. Saffarini G. Glass transition temperature and molar volume versus average coordination number in $\mathrm{Ge}_{100-\mathrm{x}} \mathrm{S}_{\mathrm{x}}$ bulk glasses. - Appl. Phys. A 59 (1994) 385-388.

10. Tichý L., Tichá H. Covalent bond approach to the glass-transition temperature of chalcogenide glasses. - J. Non-Cryst. Solids 189 (1995) 141-146.

11. Lankhorst M.H.R. Modelling glass transition temperatures of chalcogenide glasses. Applied to phase-change optical recording materials. - J. Non-Cryst. Solids 297 (2002) 210-219.

12. Mazurin O.V. Glass properties: compilation, evaluation, and prediction. - J. Non-Cryst. Solids 451 (2005) 1103-1112.

13. Thiruvikraman P.K. Rings, chains and planes: Variation of $\mathrm{Tg}$ with composition in chalcogenide glasses. - Bull. Mater. Sci. 29 (2006) 371-374.

14. Naumis G.G. Variation of the glass transition temperature with rigidity and chemical composition. - Phys. Rev. B 73 (2006) 172202-1-172202-4.

15. Freitas R.J., Shimakawa K., Kugler S. Some remarks on the glass transition temperature in chalcogenide glasses: a correlation with the microhardness. - Chalcogenide Lett. 10 (2013) 39-43.

16. Feltz A., Aust H., Blayer A. Glass formation and properties of chalcogenide systems XXVI: permittivity and the structure of glasses $\mathrm{As}_{x} \mathrm{Se}_{1-x}$ and $\mathrm{Ge}_{x} \mathrm{Se}_{1-x} .-\mathrm{J}$. Non-Cryst. Solids 55 (1983) 179190.

17. Chen P., Boolchand P., Georgiev D.G. Long term aging of selenide glasses: evidence of sub- $T_{\mathrm{g}}$ endotherms and pre- $T_{\mathrm{g}}$ exotherms. - J. Phys.: Condens. Matter. 22 (2010) 065104-1-065104-16.

18. Yang G., Bureau B., Rouxel T., Gueguen Y., Gulbiten O., Roiland C., Soignard E., Yarger J.L., Troles J., Sangleboeuf J.-C., Lucas P. Correlation between structure and physical properties of chalcogenide glasses in the $\mathrm{As}_{x} \mathrm{Se}_{1-x}$ system. - Phys. Rev. B 82 (2010) 195206-1-195206-8.

19. Zhu E., Liu Y., Sun X., Yin G., Jiao Q., Dai S., Lin C. Correlation between thermo-mechanical properties and network structure in $\mathrm{Ge}_{x} \mathrm{~S}_{100-x}$ chalcogenide glasses. - J. Non-Cryst. Solids: X 1 (2019) 100015-1-100015-7. 
20. Boolchand P., Feng X., Bresser W.J. Rigidity transitions in binary Ge-Se glasses and the intermediate phase. - J. Non-Cryst. Solids 293-295 (2001) 348-356.

21. Shpotyuk Ya., Boussard-Pledel C., Bureau B., Demchenko P., Szlęzak J., Cebulski J., Bujňáková Z., Baláž P., Shpotyuk O. Effect of high-energy mechanical milling on the FSDP-related XRPD correlations in Se-rich glassy arsenic selenides. - J. Phys. Chem. Solids 124 (2019) 318-326.

22. Adam J-L. and Zhang X. (Eds.). Chalcogenide Glasses: Preparation, properties and application, Woodhead Publ. series in Electronic and Optical Materials, Philadelphia-New Delhi, 2013. 717 pp. 23. Parsegian V.A. Van der Waals Forces. A handbook for biologists, chemists, engineers, and physicists. - Cambridge Univ. Press, Cambridge-New York-Melbourne-Madrid-Cape TownSingapore-Säo Paulo, 2006, 380 pp.

24. Pauling L. The nature of the chemical bond. - Cornell Univ. Press, New York, 1960. 656 pp.

25. Gaskell P. H. (Ed.) The Structure of non-crystalline mater.: Proc. of the symposium held in Cambridge, England on 20-23 Sept. 1976, Taylor and Francis, London, 1977. 262 pp.

26. Brodsky M.H. (Ed.). Amorphous Semiconductors, Springer-Verlag, Berlin-Heldeiberg-New York, 1979. $420 \mathrm{pp}$.

27. Bureau B., Troles J., Le Floch M., Smektala F., Lucas J. Medium range order studied in selenide glasses by ${ }^{77}$ Se NMR. - J. Non-Cryst. Solids 326-327 (2003) 58-63.

28. Bureau B., Troles J., Le Floch M., Smektala F., Silly G. Solid State ${ }^{77}$ Se NMR investigations on arsenic-selenium glasses and crystals. - Solid State Sci. 5 (2003) 219-224.

29. Shpotyuk O., Hyla M., Boyko V., Golovchak R. Reversibility windows in selenide-based chalcogenide glasses. - Physica B 403 (2008) 3830-3837.

30. Shpotyuk O., Golovchak R., Kozdras A. Physical aging of chalcogenide glasses, in: J.-L. Adam and X. Zhang (Eds.), Chalcogenide glasses: Preparation, properties and applications, Woodhead Publ. Ser. in Electronics and Optical Materials, Philadelphia-New Delhi, 2013.

31. Golovchak R., Kovalskiy A., Miller A., Jain H., Shpotyuk O. Structure of Se-rich As-Se glasses by high-resolution X-ray photoelectron spectroscopy. - Phys. Rev. B 76 (2007) 125208-125208. 
32. Golovchak R., Jain H., Shpotyuk O., Kozdras A., Saiter A., Saiter J.-M. Experimental verification of the reversibility window concept in binary As-Se glasses subjected to a long-term physical aging. - Phys. Rev. B 78 (2008) 014202-1-014202-6.

33. Shpotyuk O., Hyla M., Boyko V. Compositionally-dependent structural variations in glassy chalcogenides: The case of binary As-Se system. - Comp. Mater. Sci. 110 (2015) 144-151.

34. Blachnik R., Hoppe A., Wickel U. Die Systeme Arsen-Schwefel und Arsen-Selen Und die thermodynamischen Daten ihrer Verbindungen. - Z. Anorg. Allg. Chem. 463 (1980) 78-90.

35. Phillips J.C. Topology of covalent non-crystalline solids I: Short-range order in chalcogenide alloys. - J. Non-Cryst. Solids 34 (1979) 153-181.

36. Yang G., Gulbiten O., Gueguen Y., Bureau B., Sangleboeuf J.-Ch., Roiland C.,. King E.A., Lucas P. Fragile-strong behavior in the $\mathrm{As}_{x} \mathrm{Se}_{1-x}$ glass forming system in relation to structural dimensionality. - Phys. Rev. B 85 (2012) 144107-1-144107-8.

37. Aitken B.G. GeAs sulfide glasses with unusually low network connectivity. - J. Non-Cryst. Solids 345-346 (2004) 1-6.

38. Wright A.C., Aitken B.G., Cuello G., Haworth R., Sinclair R.N., Ross Stewart J., Taylor J.W. Neutron studies of an inorganic plastic glass. - J. Non-Cryst. Solids 357 (2011) 2502-2510.

39. Dash S., Chen P., Boolchand P. Molecular origin of aging of pure Se glass: Growth of interchain structural correlations, network compaction, and partial ordering. - J. Chem. Phys. 2017 (146) 224506-1-224506-16. 


\section{Figure captions:}

Fig. 1. Compositional variations of the macroscopic atomic densities $\rho$, mean inter-atomic spacing $d_{s}^{m}$ and molar volume $V_{m}$ in $\mathrm{g}-\mathrm{As}_{x} \mathrm{Se}_{100-x}$.

Fig. 2. Compositional variations of the overall mean bonding energy per atom $E$ in $g-\mathrm{As}_{x} \mathrm{Se}_{100-x}$ derived from estimation in respect to Tichý and Tichá algorithm [10] (red curve), as compared with statistical estimation of Yang et al. [18] and current calculations for CO CBN model (blue curve). The cohesive energies $C E$ determined per one covalent bond are plotted by black line.

Fig. 3. Linearized $\log$ - $\log$ presentation showing overall mean bonding energy per atom $E$ against inverse molar volume $V_{m}$ in $g-\mathrm{As}_{x} \mathrm{Se}_{100-x}$. The data for under-stoichiometric glasses $(x<40)$ are linearized, while evident loop is formed for over-stoichiometric glasses $(40<x<65)$.

Fig. 4. Glass transition temperature $T_{g}$ variation with the overall mean bond energy in $\mathrm{g}-\mathrm{As}_{x} \mathrm{Se}_{100-x}$. The experimental data are least-square fitted to the red line, and compared with approximation driven by Tichý and Tichá [10] (blue line).

Fig. 5. Linearized $\log$-log plot showing glass transition temperature $T_{g}$ against inverse molar volume $V_{m}$ dependence in $\mathrm{g}-\mathrm{As}_{x} \mathrm{Se}_{100-x}$. Compositional domains (1), (2) and (3) with evident linear $T_{g}$ against $1 / V_{m}$ correlations restricted by glassy specimens of the chosen chemical compositions are parameterized (see text for more details). 


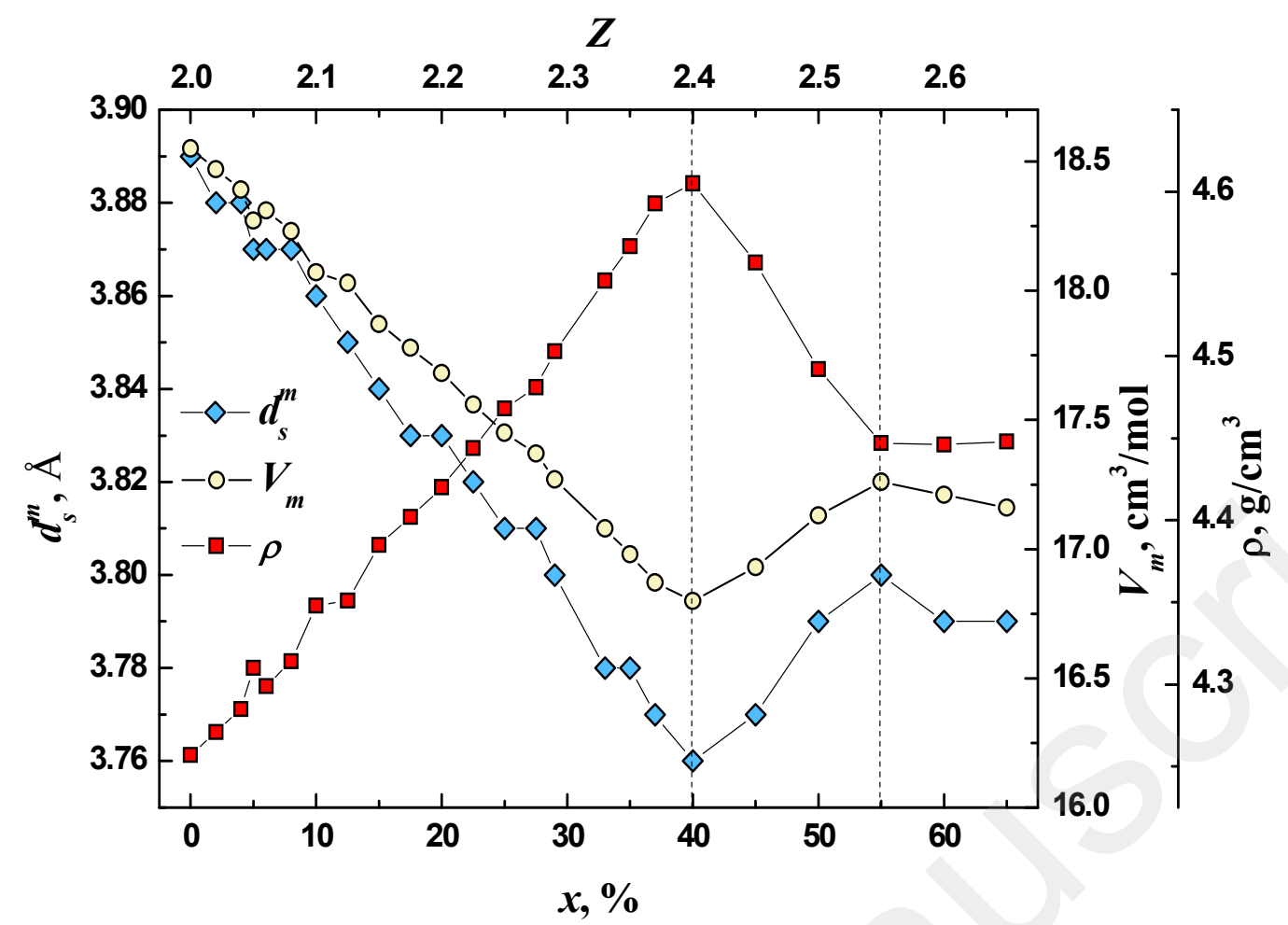

Fig. 1. Compositional variations of the macroscopic atomic densities $\rho$, mean inter-atomic spacing $d_{s}{ }^{m}$ and molar volume $V_{m}$ in g-As ${ }_{x} \mathrm{Se}_{100-x}$. 


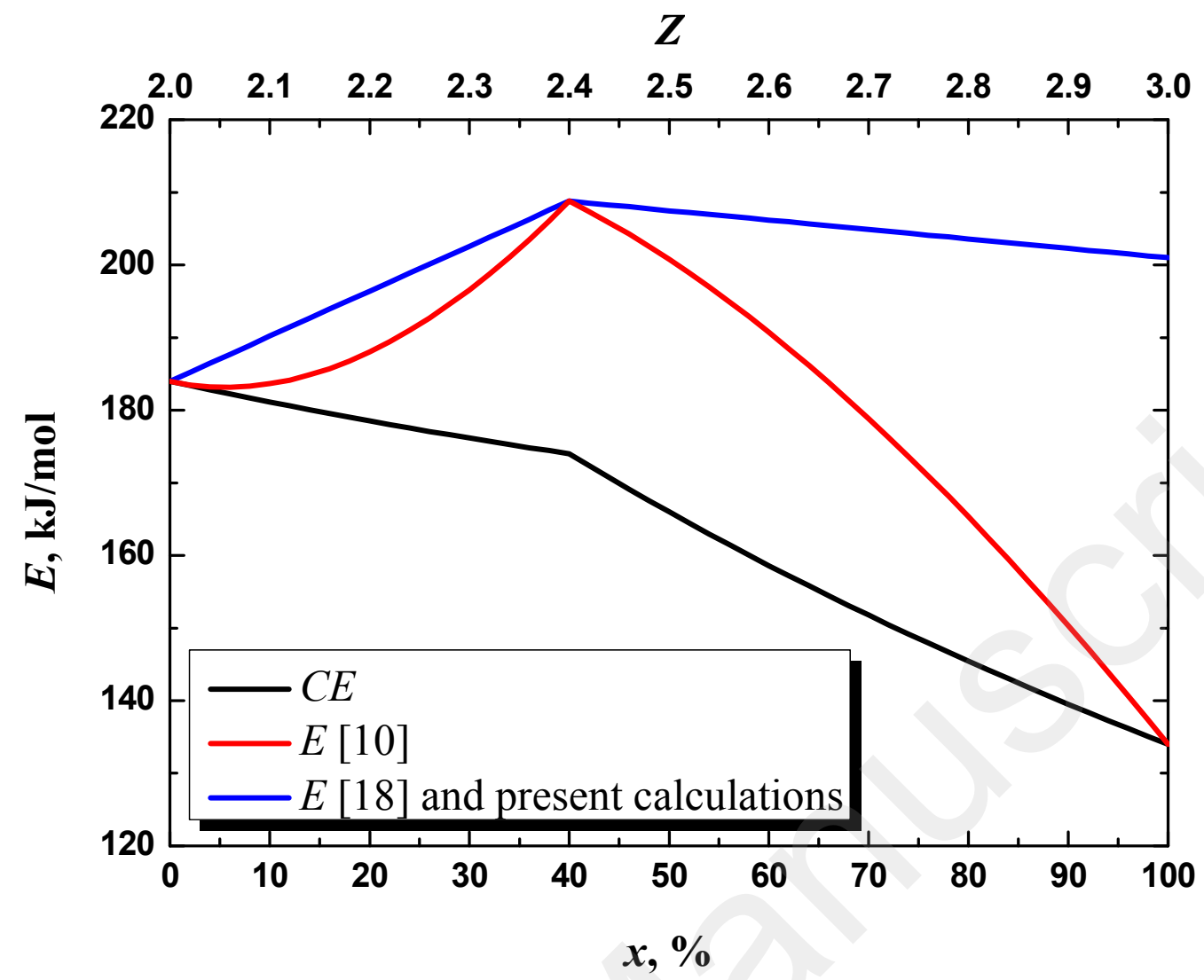

Fig. 2. Compositional variations of the overall mean bonding energy per atom $E$ in $g-\mathrm{As}_{x} \mathrm{Se}_{100-x}$ derived from estimation in respect to Tichý and Tichá algorithm [10] (red curve), as compared with statistical estimation of Yang et al. [18] and current calculations for CO CBN model (blue curve).

The cohesive energies $C E$ determined per one covalent bond are plotted by black line. 


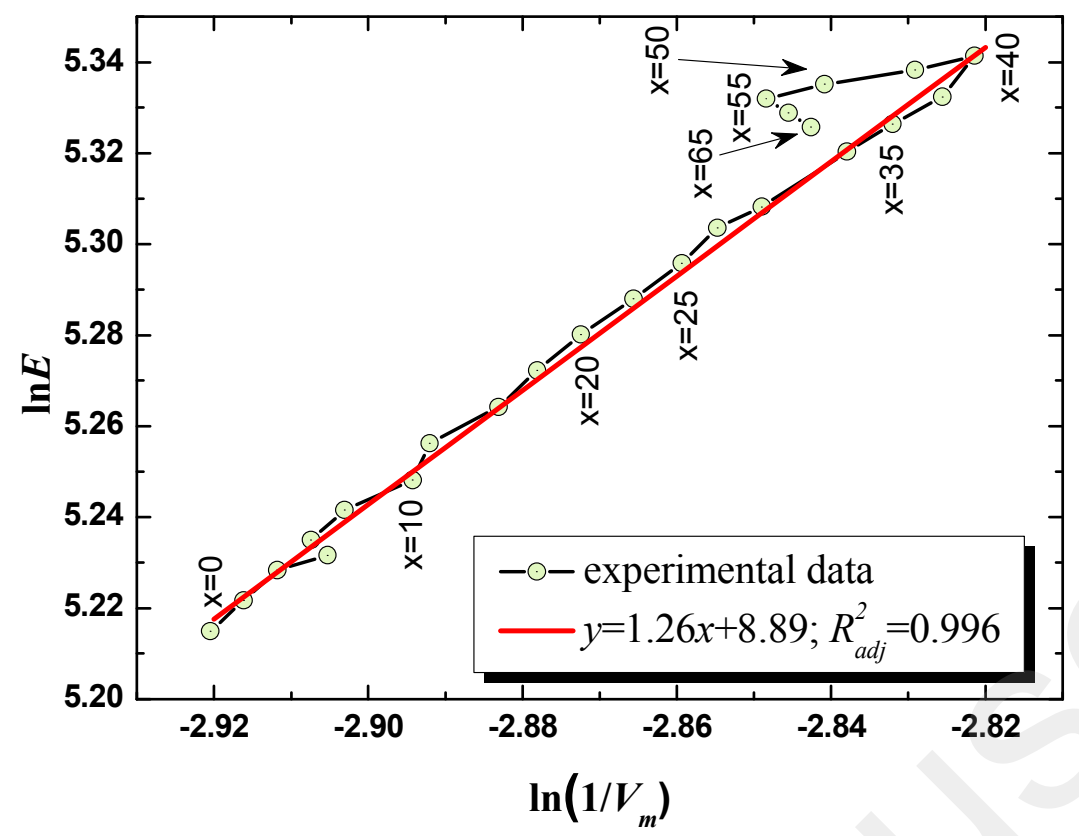

Fig. 3. Linearized $\log$-log presentation showing overall mean bonding energy per atom $E$ against inverse molar volume $V_{m}$ in $\mathrm{g}-\mathrm{As}_{x} \mathrm{Se}_{100-x}$. The data for under-stoichiometric glasses $(x<40)$ are linearized, while evident loop is formed for over-stoichiometric glasses $(40<x<65)$. 


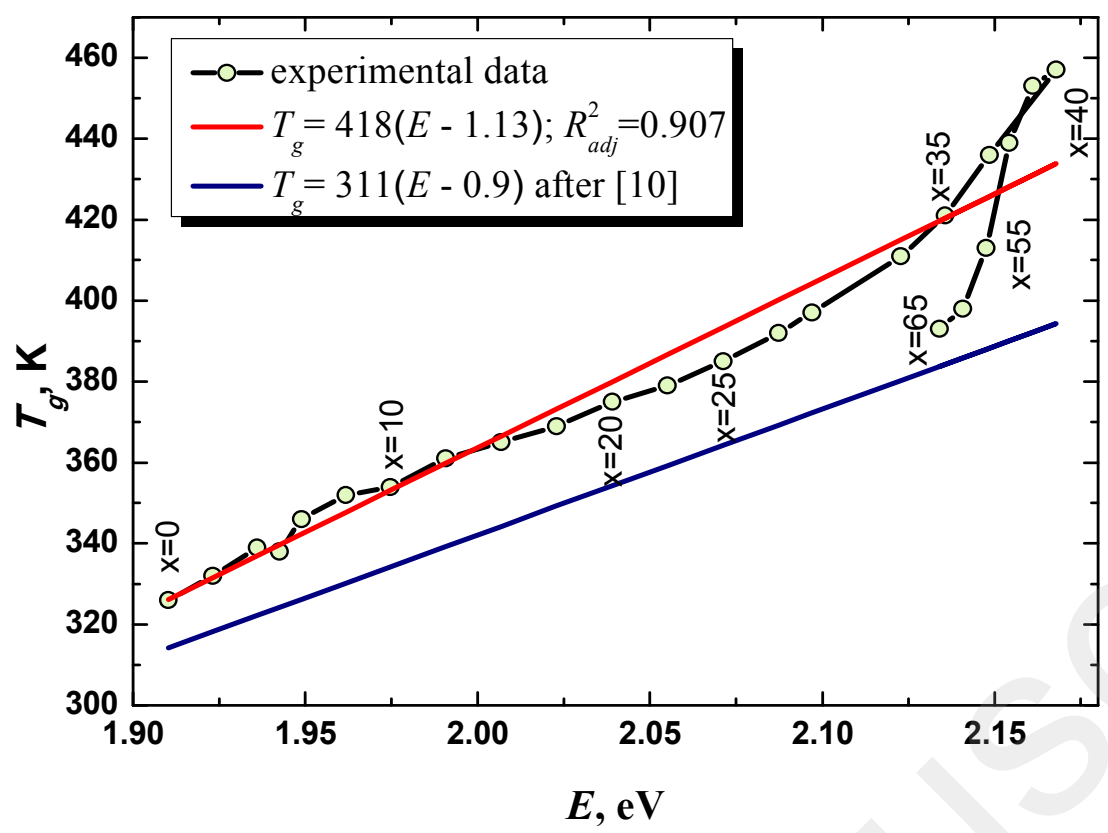

Fig. 4. Glass transition temperature $T_{g}$ variation with the overall mean bond energy in $\mathrm{g}-\mathrm{As}_{x} \mathrm{Se}_{100-x}$. The experimental data are least-square fitted to the red line, and compared with approximation driven by Tichý and Tichá [10] (blue line). 


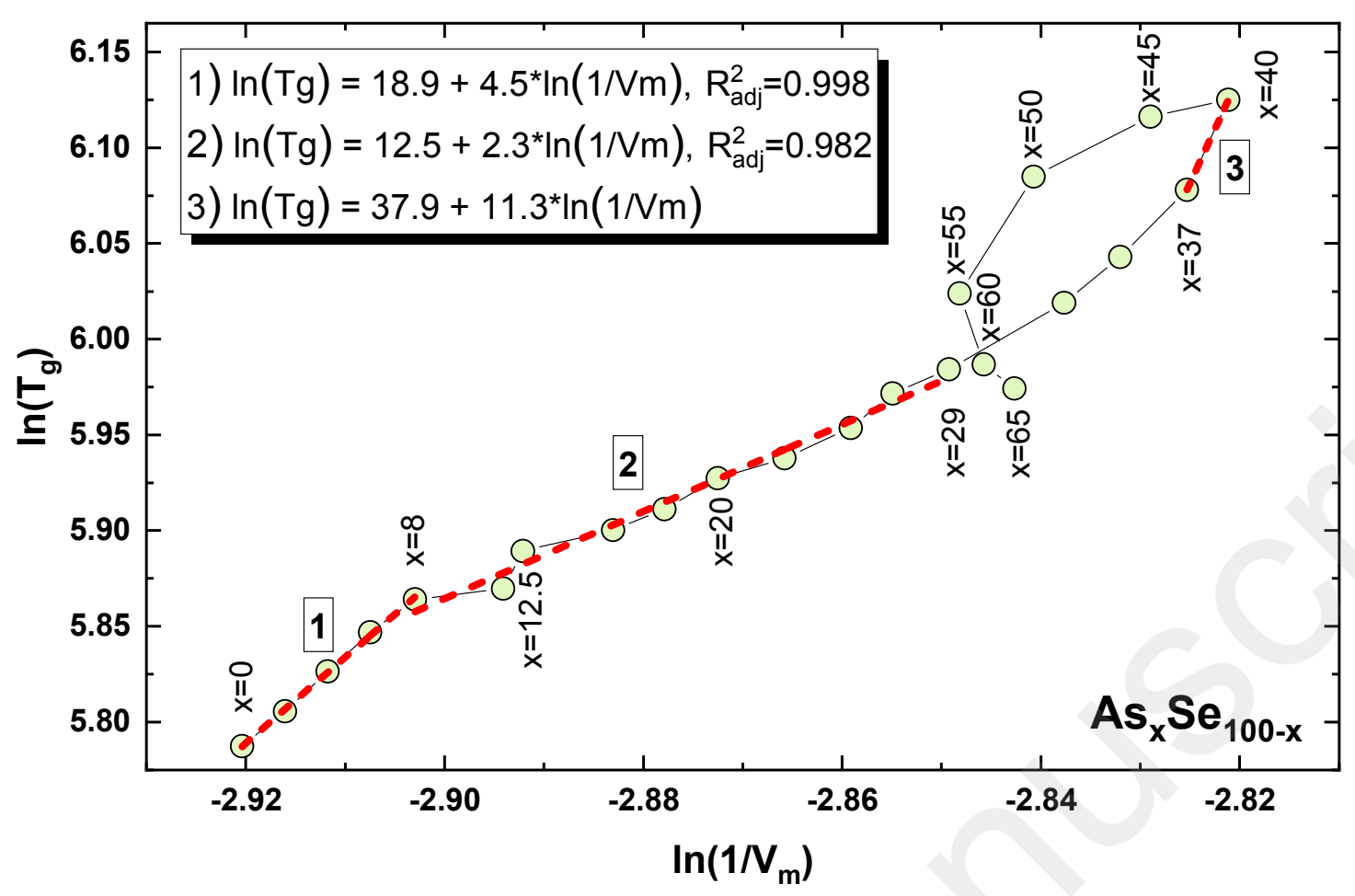

Fig. 5. Linearized $\log$ - $\log$ plot showing glass transition temperature $T_{g}$ against inverse molar volume $V_{m}$ dependence in $\mathrm{g}-\mathrm{As}_{x} \mathrm{Se}_{100-x}$. Compositional domains (1), (2) and (3) with evident linear $T_{g}$ against $1 / V_{m}$ correlations restricted by glassy specimens of the chosen chemical compositions are parameterized (see text for more details). 